\title{
C:
}

\section{A Combat Bout of Indian Monitors, Varanus bengalensis (Daudin 1802) in the Sariska Tiger Reserve, Rajasthan, India}

Debaprasad Sengupta and Parag Nigam

Wildlife Institute of India, Dehradun - 248001, Uttarakhand, India

(debaprasad.sengupta40@hotmail.com,nigamp@wii.gov.in)

Four of the 80 currently recognized species of monitor lizards - (genus Varanus; commonly referred as "Goh" in Hindi) occur in India (Uetz et al. 2018). The most abundant and widely distributed is the Indian Monitor $(V$. bengalensis; Daniel
2002). Although protected under Schedule I of the Indian Wildlife (Protection) Act, 1972 and the fact that populations are declining throughout the species' range, it was assessed as being of Least Concern for the IUCN Red List (Papenfuss et

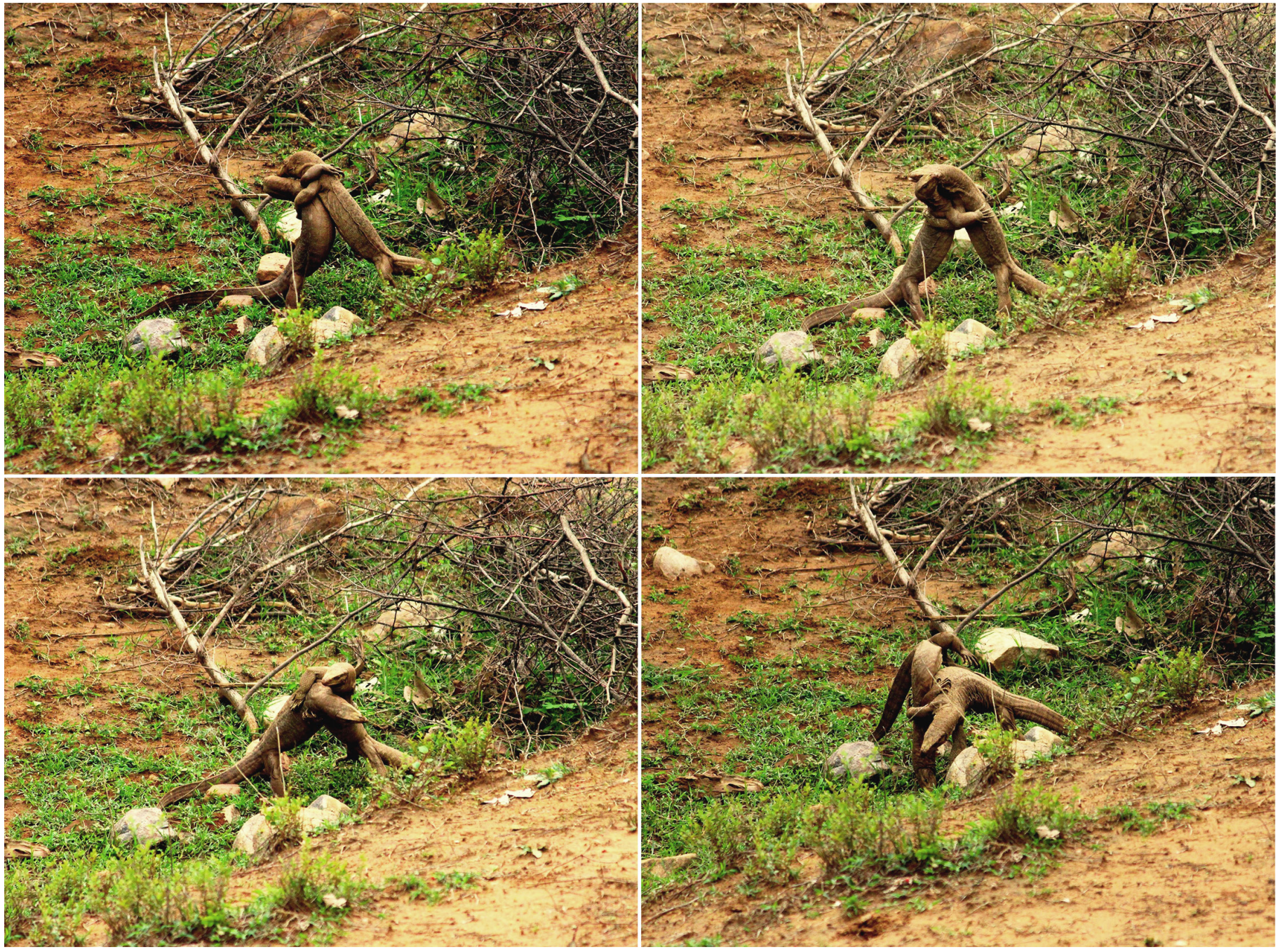

Fig. 1. Indian Monitors (Varanus bengalensis) engaged in a ritualized combat bout in the Sariska Tiger Reserve, Rajasthan, India. Photographs by Debaprasad Sengupta. 


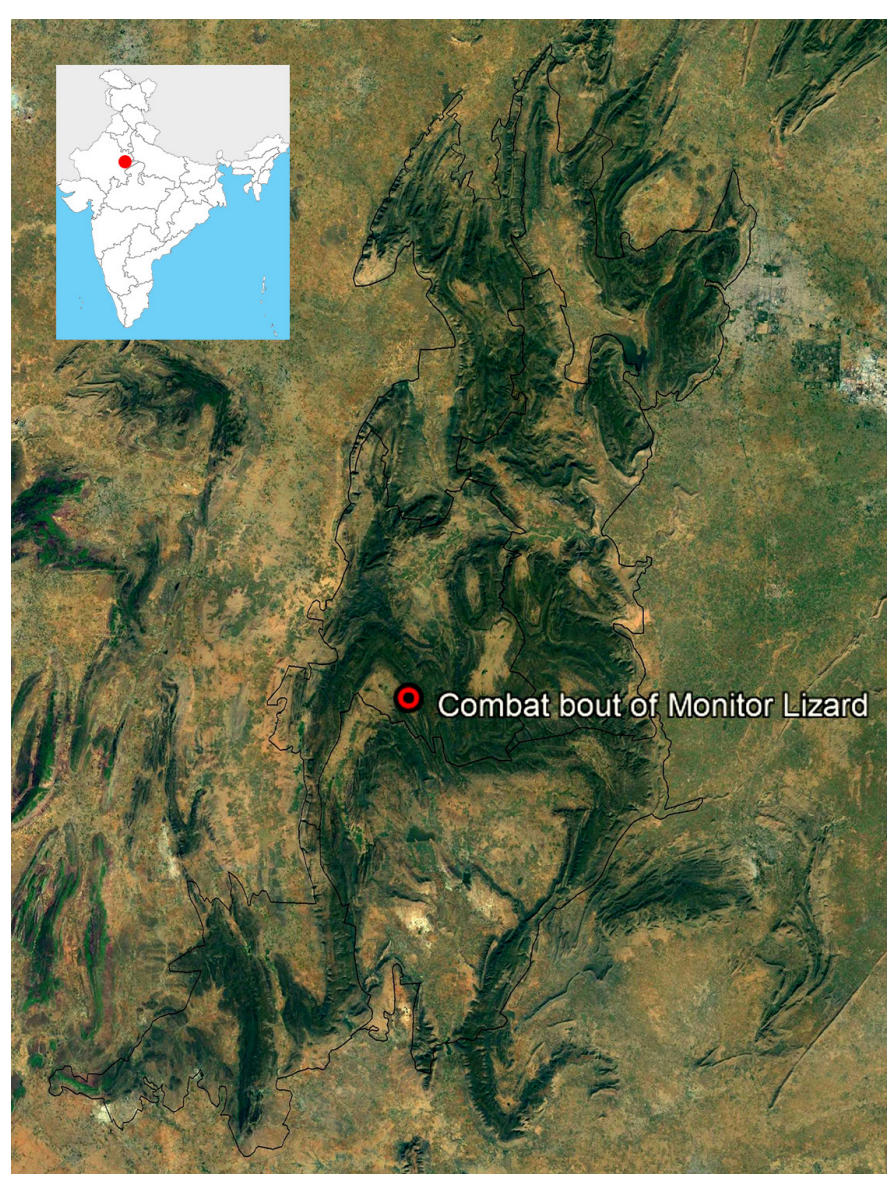

Fig. 2. Google Earth ${ }^{\odot}$ image of the Sariska Tiger Reserve in Rajasthan, India and the locality of the observation described herein.

al. 2010). Threats include habitat destruction and illegal and extensive exploitation. Adults are hunted for food and skins and the fat is used in traditional medicine (Varadaraju 2013).
Male monitors engage in ritualized combat (e.g., Auffenberg 1981). At 1648 h on 3 October 2017, we observed two adult male $V$. bengalensis (total length approx. $130 \mathrm{~cm}$ ) engage in a combat bout (Fig. 1) along the Kabri jeep road in the Sariska Tiger Reserve, Rajasthan, India $\left(27^{\circ} 19^{\prime} 38.8^{\prime \prime} \mathrm{N}, 76^{\circ} 23^{\prime} 4.7^{\prime \prime} \mathrm{E}\right.$; Fig. 2) at an elevation of 456 $\mathrm{m}$ asl. The bout lasted $43 \mathrm{~min}$ and $13 \mathrm{sec}$, during which the combatants paused only twice for less than 2 min on each occasion. Combat ended when one male knocked the head of the other on the ground. The longest known combat dance reported in the literature lasted $1.5 \mathrm{~h}$ (Daniel 2002).

\section{Acknowledgements}

This work was conducted under the auspices of the Sariska Tiger Project funded by the National Tiger Conservation Authority (NTCA) in collaboration with the Wildlife Institute of India and the Rajasthan Forest Department. Forest officials of the Sariska Tiger Reserve granted permission to work in the reserve. Ratanlal Gurjar and Rajesh Meena assisted us in the field.

\section{Literature Cited}

Auffenberg, W. 1981. Combat behaviour in Varanus bengalensis (Sauria: Varanidae). Journal of the Bombay Natural History Society 78: 54-72.

Daniel, J.C. 2002. The Book of Indian Reptiles and Amphibians. The Bombay Natural History Society \& Oxford University Press, Mumbai, India.

Papenfuss, T., S. Shafiei Bafti, M. Sharifi, D. Bennett, and S.S. Sweet. 2010. Varanus bengalensis. The IUCN Red List of Threatened Species 2010: e.T164579A5909661 (http://dx.doi.org/10.2305/IUCN.UK.2010-4.RLTS. T164579A5909661.en).

Uetz, P., P. Freed, and J. Hošek (eds.). 2018. The Reptile Database (http://www. reptile-database.org).

Varadaraju. 2013. Present status of three monitor lizards (Varanus bengalensis, V. flavescens and $V$. salvator) in the Sunderbans. Records of the Zoological Survey of India 113(Part-1): 203-210. 